\title{
Blade Displacement Measurements of the Full-Scale UH-60A Airloads Rotor
}

\author{
Danny A. Barrows ${ }^{1}$ \\ NASA, Langley Research Center, Hampton, Virginia, 23681 \\ Alpheus W. Burner ${ }^{2}$ \\ Jacobs Technology, Inc., Hampton, Virginia, 23681 \\ Anita I. Abrego ${ }^{3}$ and Lawrence E. Olson ${ }^{4}$ \\ NASA, Ames Research Center, Moffett Field, California, 94035
}

\begin{abstract}
Blade displacement measurements were acquired during a wind tunnel test of the fullscale UH-60A Airloads rotor. The test was conducted in the 40- by 80-Foot Wind Tunnel of the National Full-Scale Aerodynamics Complex at NASA Ames Research Center. Multicamera photogrammetry was used to measure the blade displacements of the four-bladed rotor. These measurements encompass a range of test conditions that include advance ratios from 0.15 to unique slowed-rotor simulations as high as 1.0, thrust coefficient to rotor solidity ratios from 0.01 to 0.13 , and rotor shaft angles from -10.0 to 8.0 degrees. The objective of these measurements is to provide a benchmark blade displacement database to be utilized in the development and validation of rotorcraft computational tools. The methodology, system development, measurement techniques, and preliminary sample blade displacement measurements are presented.
\end{abstract}

\section{Nomenclature}

$\mathrm{C}_{\mathrm{T}} \quad=$ rotor thrust coefficient

$\sigma \quad=$ rotor solidity, total area of blade/area of rotor disk

$\mathrm{C}_{\mathrm{T}} / \sigma \quad=$ ratio of thrust coefficient to rotor solidity

$\mathrm{r}=\quad=$ radial blade location measured from the shaft axis, in

$\mathrm{R} \quad=$ blade radius, in

$\mu \quad=$ advance ratio, forward flight speed/speed of the rotor tip

$\psi \quad=$ rotor azimuth, deg (full aft $=0^{\circ}$ )

$\mathrm{Z} \quad=$ vertical dimension parallel to rotor shaft, in

$\Delta \mathrm{Z} \quad=$ elastic vertical displacement, in

\section{Introduction}

$\mathbf{B}$

LADE displacement (BD) measurements are used to help resolve blade shape and position, which include attitude, deflection, and lead-lag angle. When combined with rotor blade airloads and wake measurements, a comprehensive dataset is formed that directly relates rotor performance to the physical properties of the flow. Rotor blade displacement information is critical for the development of improved rotorcraft design and analysis techniques based on "first principles" and can potentially be used to help validate CFD-CSD coupled solvers. More specifically, progress toward more tightly coupled multi-disciplinary, higher fidelity techniques is enhanced by the availability of detailed experimental measurements obtained under conditions representative of actual flight conditions. Blade displacement measurements are also crucial in the design and evaluation of rotor systems that utilize morphing technologies such as active twist to enhance performance and minimize noise and vibration.

\footnotetext{
${ }_{1}^{1}$ Aerospace Engineer, RD/Adv Sensing and Optical Mea Branch, m/s 493, AIAA Senior Member.

${ }^{2}$ Aerospace Engineer, ROME/R \& D Engineering, m/s 267, AIAA Associate Fellow.

${ }^{3}$ Aerospace Engineer, AU/Aeromechanics Branch, m/s N243-12.

${ }^{4}$ Aerospace Engineer, AU/Aeromechanics Branch, m/s N243-12, AIAA Associate Fellow.
} 
Explicit measurements of rotor blade displacements are relatively rare. Traditionally, blade displacements have been measured with strain gauges imbedded in the rotor blade. Due to limitations in blade size and channels on the slip ring, the number of possible sensors is usually insufficient to fully resolve the blade geometry. As an alternative, optical methods can be used to provide a fairly accurate description of the blade geometry over its entire length with the additional benefit of reduced fabrication costs and sensor count. ${ }^{1}$ For instance, in 2001, the stereo pattern recognition measurement technique was used to map blade displacement during the HART II, Higher Harmonic Control Aeroacoustic Rotor Test in the German-Dutch, Duits Nederlands Windtunnel (DNW). ${ }^{2}$

In preparation for the 2010 UH-60A Airloads wind tunnel test, multi-camera photogrammetric blade displacement measurements were obtained during the 2008 Smart Material Actuated Rotor Technology (SMART) and the 2009 Individual Blade Control (IBC) tests in the USAF National Full-Scale Aerodynamics Complex (NFAC) 40- by 80-Foot wind tunnel. ${ }^{3}$ The primary purpose of the BD measurements during these two tests was to progressively test system hardware and techniques in preparation for the 2010 NFAC Airloads test. Prior to the 2008 NFAC test, a baseline two-camera blade displacement image acquisition system was configured and laboratory tested at NASA Langley Research Center. This prototype system helped define the methodology used in the buildup of the photogrammetric approach used during the three subsequent NFAC rotor tests.

During the 2008 SMART test ${ }^{4}$, sequences of synchronized images from two cameras were acquired for one targeted blade in one 90 deg quadrant on the advancing blade side of the rotor disk. The camera pair, spaced approximately 32-feet apart, observed the nearly 17-foot long rotor blade during a forward flight condition of 123 knots and a rotor rotation rate of $6.5 \mathrm{~Hz}$. A second test, the IBC experiment, consisted of a full-scale UH-60A rotor installed on the NFAC Large Rotor Test Apparatus (LRTA). ${ }^{5}$ The blade displacement system was expanded to acquire sequences of synchronized images of two 27-foot blades from four cameras covering two quadrants of the rotor disk. The location of one camera pair was identical to that used in the SMART test and the second camera pair was installed across the test section centerline at locations symmetrical to the first pair. Image data were captured during this test at simulated forward flight conditions as high as 175 knots, advance ratio of 0.4 , and a rotor rotation rate of $4.3 \mathrm{~Hz}$. During these two NFAC tests, valuable but limited test time was available for the BD system and controlled data sets were obtained in only a few days in each test.

The third NFAC test entry, the UH-60A Wind Tunnel Airloads Test (Fig. 1), was conducted in early $2010{ }^{6}$ The test was a joint venture between NASA and the U.S. Army to acquire extensive, accurate data sets to aid in the development of advanced helicopter systems design methodologies. Sequences of synchronized images were captured for all four rotor blades as they rotated through the entire rotor azimuth. Data were acquired throughout the test program creating an extensive collection of rotor blade displacement data covering a wide range of test conditions. The measurements compliment and expand the database available from flight tests of the UH-60A airloads rotor completed in $1993 .^{7,8}$

For the three NFAC tests described above, the BD system progressively doubled in size and complexity for each test. A single PC assembly with two-cameras was used for the SMART Test, two PCs with four-cameras were used for the IBC Test, and four PCs with eight-cameras were used for the Airloads Test. The progress made during the first two test entries helped minimize the risk, time, and level of effort required to successfully acquire extensive benchmark data sets during the Airloads test.

The remainder of the paper is organized as follows. In Section II the methodology based on close-range photogrammetry and hardware are introduced. Section III describes the camera calibrations and necessary supporting measurements. In Section IV image acquisition and processing are discussed. Finally, Section V presents preliminary sample data results including root pitch, flap, lag as well as elastic vertical displacement for all four blades over the full azimuthal range. At the time of this publication an extensive data reduction effort for the 2010 NFAC Airloads test is ongoing. 


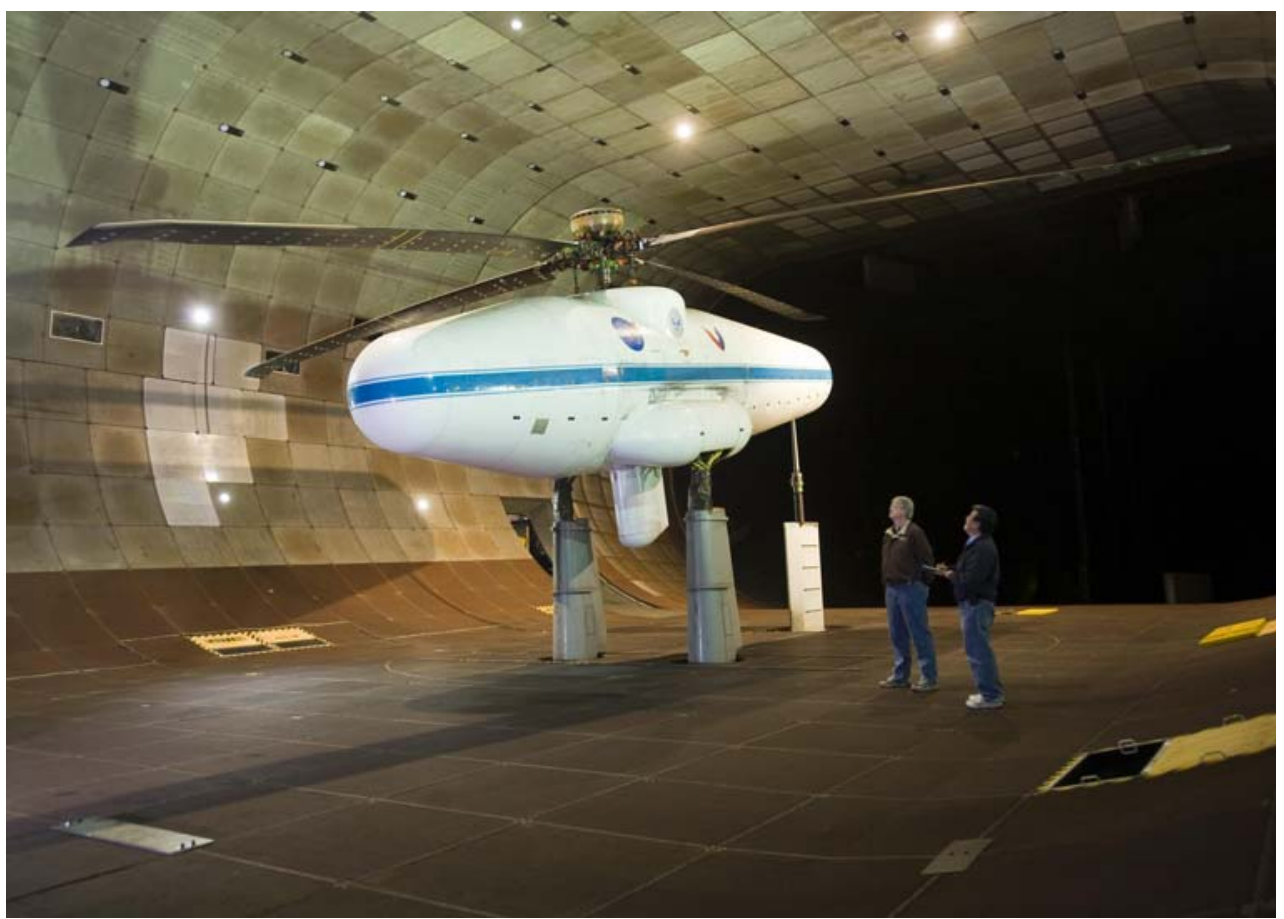

Figure 1. UH-60A Airloads rotor system installed on LRTA in the NFAC 40- by 80-foot test section.

\section{Methodology and Hardware}

The experimental technique is based on the principals of digital close-range photogrammetry. ${ }^{9}$ Eight cameras located below the rotor disk (Fig. 2), synchronized with the rotor azimuth, simultaneously capture 48 retro-reflective targets on the lower surface of each blade at an image-set acquisition rate of once per rotor revolution. Each image set acquired at a specified rotor azimuth is used to determine the instantaneous position of each of the four rotor blades. Image data were taken for up to 60 consecutive revolutions to document the instantaneous and mean (via ensemble average) deformation of each blade at a specific azimuth. This process is repeated at up to 40 rotor azimuths to document the blade deformation throughout the rotor disk. Additional details of the methodology used to obtain measurements of the elastic displacement of a full-scale rotor are presented below.

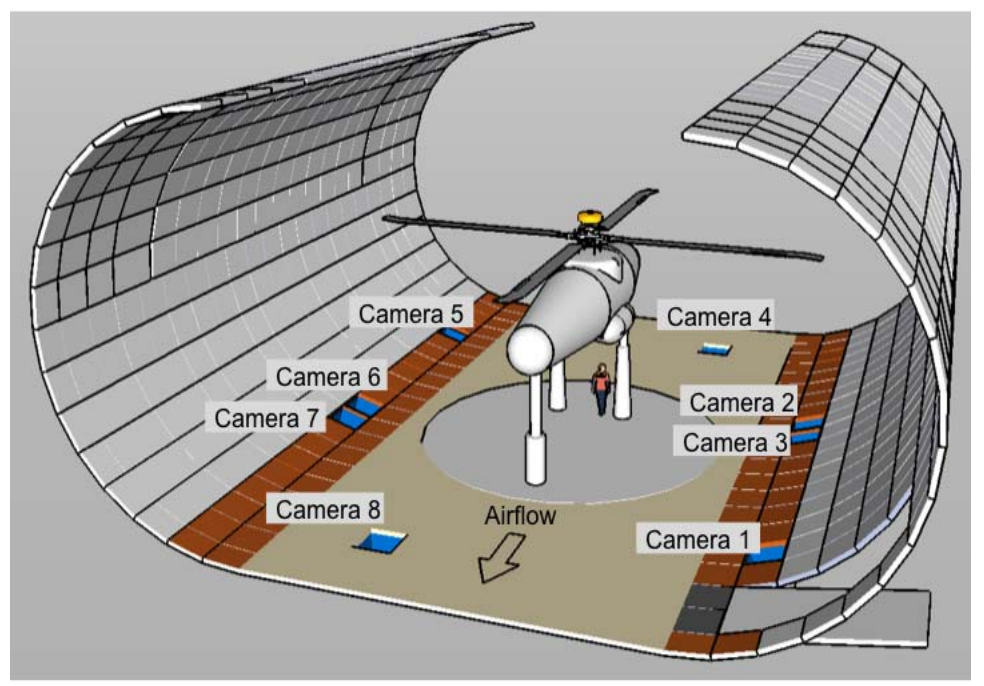

Figure 2. Schematic showing the floor cavity locations in which digital cameras and strobes are installed. 


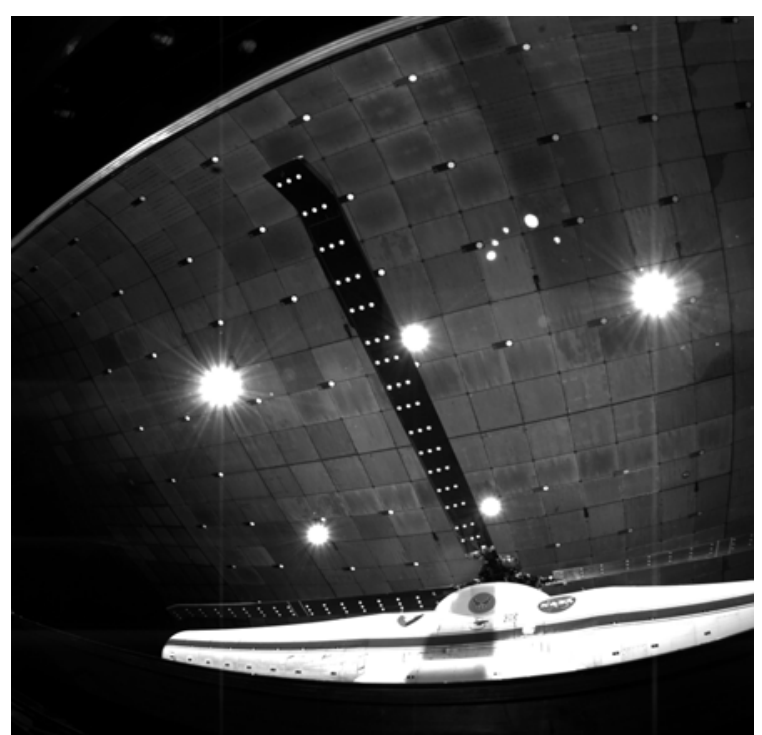

Figure 3. Rotor blades showing 2-inch diameter retro-reflective targets.
The retro-reflective targets necessary for blade measurements were cut from 4-mil thick 3M Scotchlite 7610, high reflectance adhesive tape. The lower surface of each rotor blade was targeted with 48, two-inch diameter retro-reflective targets, three per radial station, uniformly spaced at approximately 0.05R intervals between the blade cuff and blade tip (Fig. 3). Additionally, eighty-four, six-inch diameter targets were installed onto the test-section ceiling in order to determine camera locations, pointing angles, and distortion as discussed in Section III.

A top-view of the four rotor blades, LRTA and camera locations in the test section is illustrated in Fig. 4. The blades rotate counter-clockwise and are numbered 1 to 4 , in the order they would pass by a stationary observer. The basic construction of all four UH-60A blades is nearly identical. ${ }^{10}$ The principal mechanical difference among them is blade 1 is instrumented with pressure sensors and blade 3 is instrumented with strain gauges. ${ }^{7,11}$ The four quadrants that make up the rotor disk are defined as Q-I thru Q-IV.

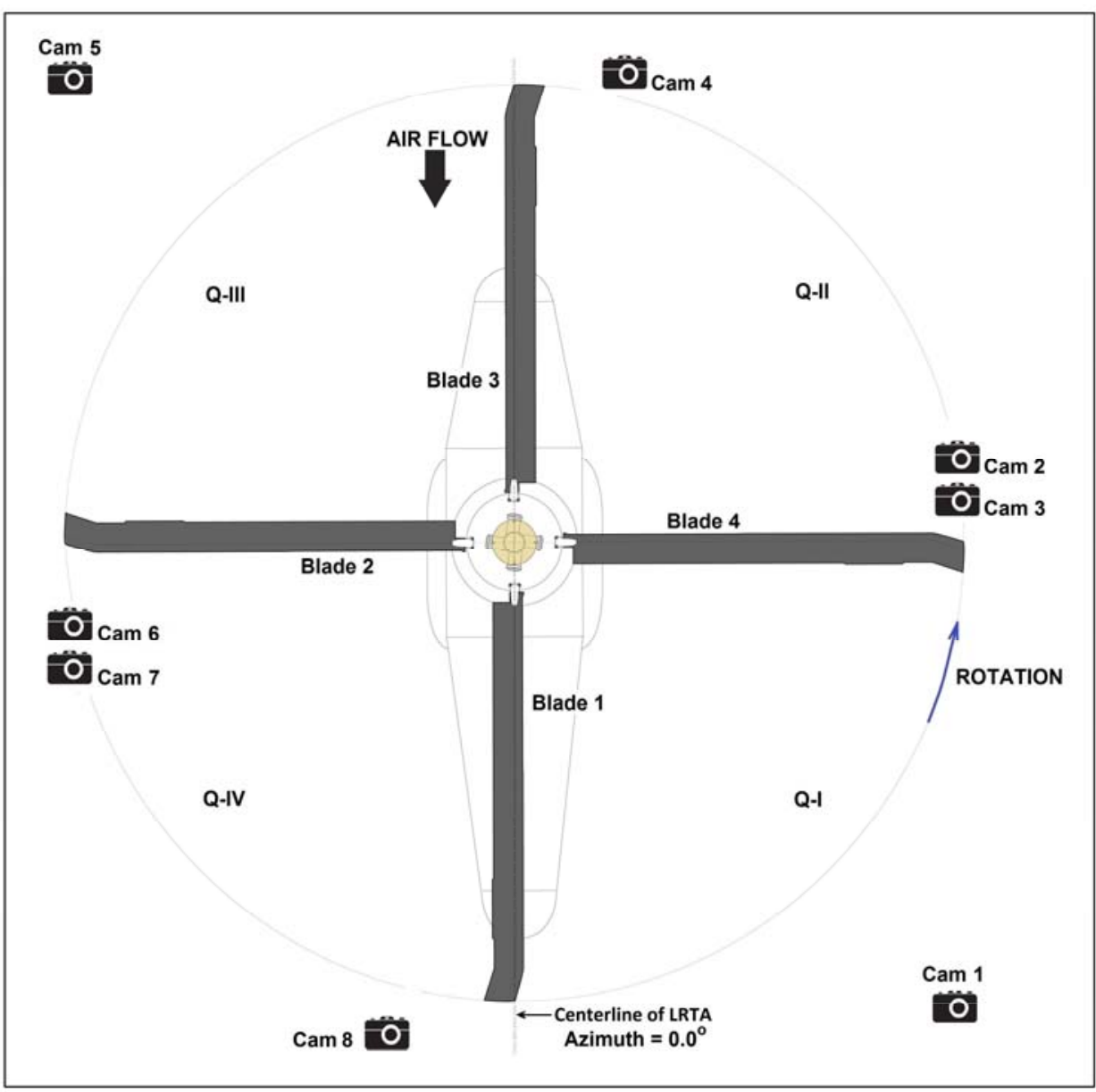

Figure 4. Top-view of the UH-60A rotor defining the rotor quadrants, blade and camera identification numbering, and approximate camera locations. 
The eight BD cameras positioned around the model were strategically placed below the blades and looking up (Figs. 2 and 4) to optimize viewing of the retro-reflective blade targets based on experience gained from the SMART/IBC test data and analytical modeling of target visibility. ${ }^{3}$ Two of the eight cameras nominally viewed each rotor quadrant. Cameras 1 and 2 were nominally pointed at Q-I, cameras 3 and 4 at Q-II, etc. The combined eight cameras captured time-synchronized image sequences covering the rotation of each blade through the full 360degree rotor azimuth. These camera locations were not symmetrical about the rotor shaft due to differences in how the blades behaved in each quadrant as seen during testing. The view from a given camera was not limited to a single quadrant so that, for a blade located at an arbitrary azimuth location, at least three-camera photogrammetric intersections of the blade targets are usually possible. Often four or five and occasionally six-camera intersections are possible on portions of the blades.

The cameras were securely anchored in test section floor cavities to view the lower surfaces of the blades through protective low-reflectance glass windows (Fig. 5). Target illumination was provided by Perkin-Elmer Machine Vision 7060-10 xenon flash-lamp $50 \mathrm{~mJ}$ strobes with pulse duration of 10 micro seconds (full width at 1/3 maximum). Fiber optic bundles positioned as near as possible to the optical axes of each camera lens routed the light from each strobe to illuminate the targets. This near on-axis lighting maximized the light return from the blade and ceiling retro-reflective targets. Roughly $50 \%$ of the fiber bundles were capped with focusing lenses to help increase illumination in areas of the rotor disk where the camera view of the targets was highly oblique, often less than $30^{\circ}$, with corresponding lower return from the retro-reflective targets. The strobes and cameras were triggered based on rotor shaft azimuth location with the strobe light pulses occurring within the integration time of the CCD video cameras.

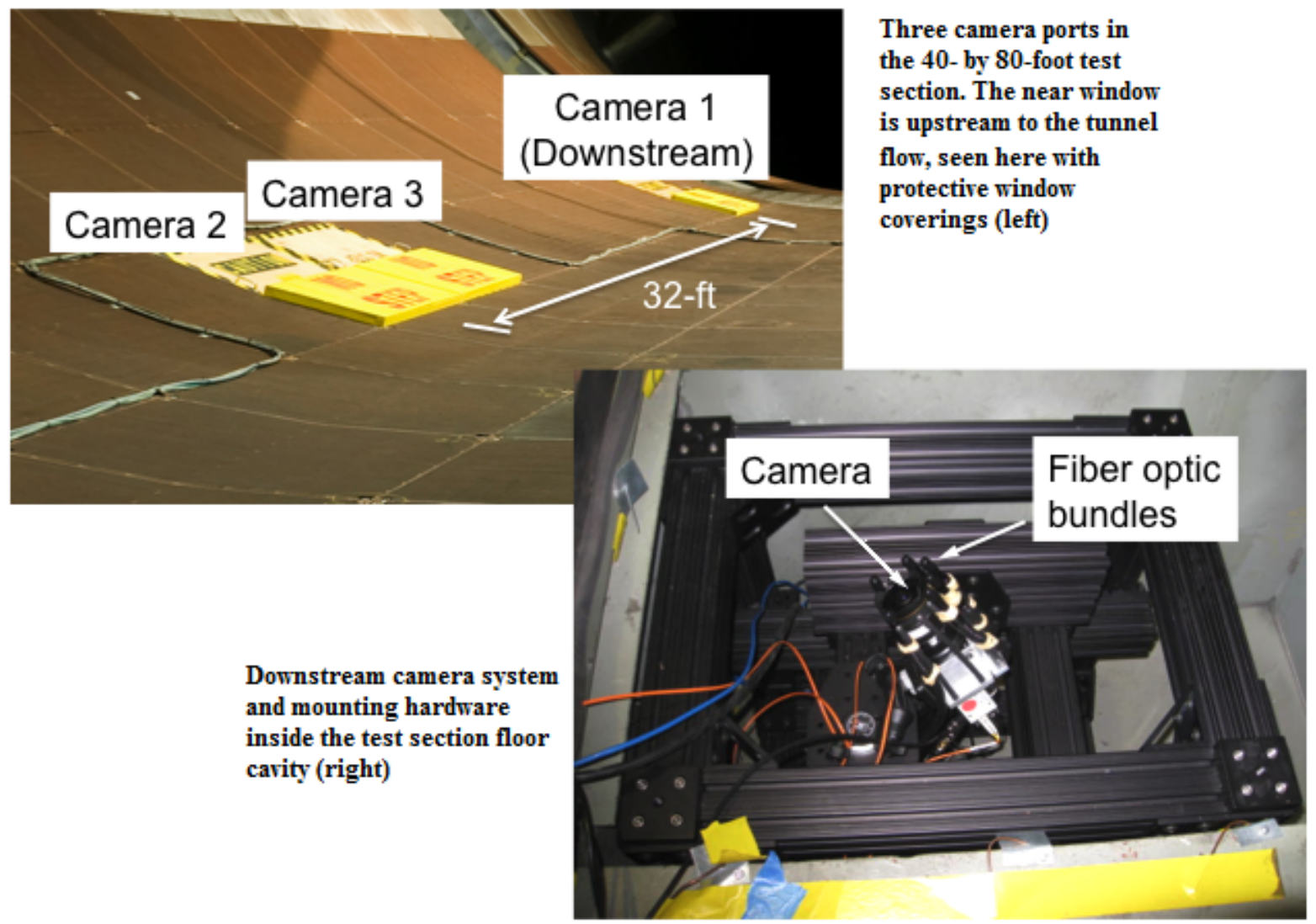

Figure 5. Camera system and mounting hardware inside the test section floor cavity.

For each camera an image field-of-view covering the azimuth range of at least $90^{\circ}$ was needed in order to capture the full span of the rotor blades. The overall translation experienced by the rotor due to angle of attack changes, combined with the range of possible blade flap and elastic blade deformation, further expanded the lens field-of-view requirements. As a result, covering the full range of blade motion (given the camera location constraints of the NFAC) required that fish-eye lenses (Nikon $10.5 \mathrm{~mm} \mathrm{f} / 2.8 \mathrm{DX}$ ) be used. Short focal-length "fish- 
eye" lenses are normally not used in photogrammetry since obtaining sufficiently accurate distortion corrections can be problematic. However, camera/lens calibrations discussed in Section III can partially correct troubling lens distortions that otherwise reduce the accuracy of the measurements. Additionally, because of the extreme distortion of fish-eye lenses near the corners of the field-of-view, special care was taken when orienting and aiming the cameras to keep the rotor hub and blade tips away from the corners of the field of view.

The image acquisition hardware consisted of four PC's running Windows XP Professional ${ }^{\circledR}$, each with a Matrox Helios PCIX ${ }^{\circledR}$ frame grabber board that was Camera Link ${ }^{\circledR}$ interfaced to two 4-Mega-pixel, 12-bit CCD progressive scan Imperx IPX-4M15-L digital cameras. The pixel resolution of the cameras was $2048 \times 2048$. Acquisition software included NASA's Rotor Azimuth Synchronization Program (RASP) rotor encoder ${ }^{12}$ and WingViewer image acquisition software ${ }^{13}$, coupled with xenon flash lamps. Prior to the start of forward flight testing, the BD system setup focused on ensuring high image quality (particularly lighting), optimal orientation angles of the cameras, and adequate coverage on the camera image planes across the complete rotor disk for the anticipated test conditions.

At each primary BD test condition, typically defined by thrust, advance ratio and angle of attack, sets of images were acquired over a range of azimuths. Each image set acquired at a specified rotor azimuth, combined with camera calibrations, is used to determine the instantaneous position of each of the four rotor blades. The number of images acquired is a primary factor determining the precision of ensemble averages required for measurements such as blade lag, flap and twist distributions. Once the number of images was set, data at a given rotor azimuth was acquired by phase locking with the rotor shaft azimuth encoder. The eight cameras were synchronized and simultaneously captured the forty-eight retro-reflective targets on the lower surface of each blade. For the nominal rotor rotation rate of 258 RPM, one image set was captured every 0.23 seconds.

In general, the blade and azimuth combination exhibiting the most dynamic rev-to-rev displacement variation determined the number of images that should be obtained at each azimuth for a sweep of the entire rotor disk. For example, a large image set for an Airloads primary BD test condition consisting of 60 revolutions of data per azimuth with eight cameras and 40 rotor azimuths produced 19,200 individual images. The time required to acquire 60 images at each of the 40 rotor azimuths was approximately 14 seconds, leading to a total data acquisition time of less than 10 minutes to cover the entire rotor disk. Data acquisition time proportionally increased during slowed rotor testing at RPMs of 167 and 105.

In an effort to ensure the measurements are useful to analysts for some years to come, BD measurement accuracy requirements and objectives for the Airloads Test Program are relatively stringent, namely $0.1^{\circ}$ for blade twist distribution. This twist accuracy requires the relative location of adjacent targets at a given radial station be determined to within 0.020 inches in the rotor coordinate system.

\section{Calibrations and Supporting Measurements}

Determining the blade geometry in the shaft coordinate system from digital images captured by the cameras is basically dependent on two system calibrations: 1) the interior calibration of the cameras (lens/sensor parameters) and 2) the exterior calibration of the cameras (camera locations and pointing angles). In addition, the measurement of the targets on the blades (relative to the radial station and the local airfoil chord) establishes a reference for determination of the elastic bending and twist as discussed later. Also the orientation of the rotor shaft must be known to orient the three dimensional data in the tunnel coordinate system to the rotor shaft coordinate system. Some of the interior calibrations and initial blade target measurements are accomplished prior to the start of testing. Descriptions of each of these calibrations and necessary measurements are provided in the following sections.

\section{A. Interior Camera Calibrations}

Prior to mounting the cameras in the tunnel the photogrammetric principal distance and principal point for each of the 4-mega pixel, 12-bit gray scale cameras are determined. Four of the cameras had been previously calibrated for the Smart and IBC tests with non-standard, specialized laboratory techniques ${ }^{14}$ and were not recalibrated for the Airloads test. The four new cameras that were added for the Airloads test (for a total of eight cameras) were calibrated with a more standard technique known as analytical self-calibration ${ }^{15}$ in addition to laboratory calibration. Self-calibration is an established technique often used by the photogrammetric community to determine camera calibration by combining, in a large sparse nonlinear least squares solution, the image data from multiple and diverse views of a target field that covers much of the field-of-view of the camera. For these calibrations the cameras were positioned at a distance from the large target field at approximately the same camera-to-blade distance used during the NFAC test. Preliminary comparisons of the results from the laboratory and the more established self-calibration technique have produced very similar results. 


\section{B. Distortion and Exterior Camera Calibrations}

After all eight-cameras are firmly anchored into their final positions in the test section, camera calibrations are used to determine the location and orientation of each camera relative to the test section as well as distortion coefficients throughout testing. The constellation of 84 six-inch diameter retro-reflective targets used for calibration are distributed over the test-section ceiling, as shown in Fig. 6, with approximately uniform 96-inch spacing between targets. More than half of the ceiling targets are located on large 80-ton clamshell doors that are used to gain access into the test section. One of these two-doors is shown in Fig. 7 in open position, exposing the inside of the test section where test articles are installed. The location and orientation of this ceiling target field, relative to the test section, is determined using a commercial photogrammetry measurement system, V-STARS, developed by Geodetic Systems Inc $\odot{ }^{16}$

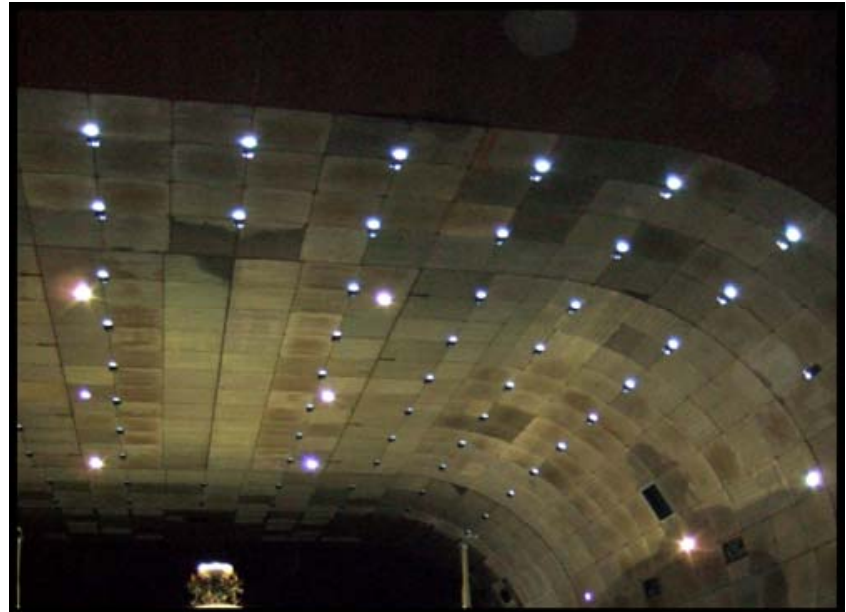

Figure 6. Six-inch diameter retro-reflective calibration targets installed on the test section ceiling.

The ceiling mappings that were obtained without flow provided target locations with a standard deviation of 0.04 inches. Analyses of the IBC and Airloads test data determined that calibration corrections for possible thermal expansion caused by changes in test-section shell temperature are not required. The effects from these changes fall

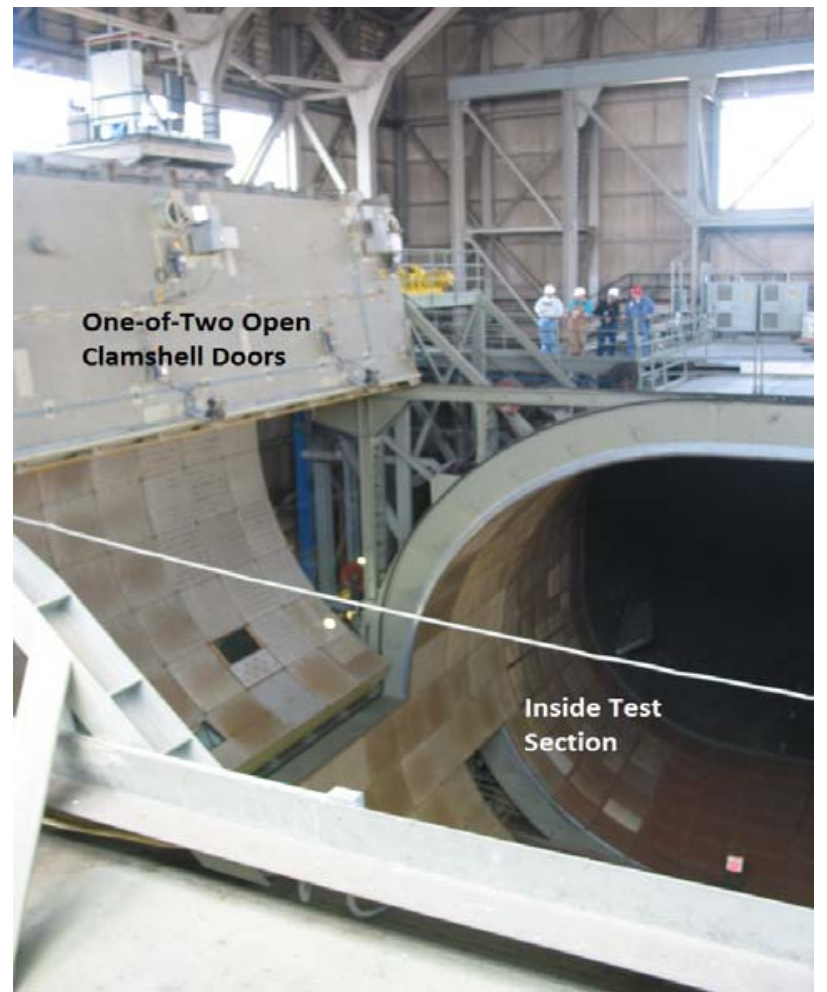

Figure 7. View from above NFAC 40- by 80-Foot Wind Tunnel test section with clamshell (ceiling) door open. within the noise levels of the measured locations. To account for changes potentially caused by opening and closing the clamshell doors, the ceiling targets were re-measured after each closing of the doors. In addition, it is possible that these massive doors could move under forward flight conditions due to the reduction in the test section static pressure. Investigations are under way to potentially refine the exterior camera calibrations to account for this possible effect.

These distortion coefficients and resection parameters are determined throughout the test with an iterative technique that incorporates linear least squares for distortion and nonlinear least squares for the camera pointing angles and location. This has the advantage of incorporating any additional distortions from the cavity windows as well as allowing for tracking of the distortion and resection parameters throughout the test. For instance, a small change in the orientation and location of one of the cameras noted part way into the test is accommodated. (This change correlated with the replacement of instrumentation connected to the camera.) Preliminary results show nearly negligible changes in distortion parameters throughout the test. Thus it should be valid to use a single set of distortion coefficients for each camera derived from the mean of distortion throughout the test. 


\section{Blade Target Measurements}

Prior to blade installation on the LRTA, the spatial locations of all 48 two-inch diameter targets on the lower surface of the blades were measured using the V-STARS photogrammetry system with standard deviations of typically less than 0.001 inch. These maps of static target location measurements were determined with the lower surfaces of the blades facing up, on sawhorses, in a way to help eliminate elastic bending due to gravity. The location of two 1-inch diameter blade-to-spindle-attachment bolt holes were included in this mapping, providing a measurement of the radial location of each target and a reference chord line defining zero static twist of the blade. Also included in this measurement were the locations of the trailing edge of the blades, at each targeted radial station. These data provide the basis for computing, at each radial station, the location and orientation of the chordline from the photogrammetric measurement of surface-target locations in the wind tunnel coordinate system acquired during forward flight testing.

\section{Instrumentation Hat Target Measurements}

A transformation of measured target locations, displacement, blade pitch, etc from the wind tunnel coordinate system into the rotor coordinate system requires knowledge of the orientation and location of the rotor shaft relative to vertical in the tunnel coordinate system. The transformation can be made, at least to the first order, based on the

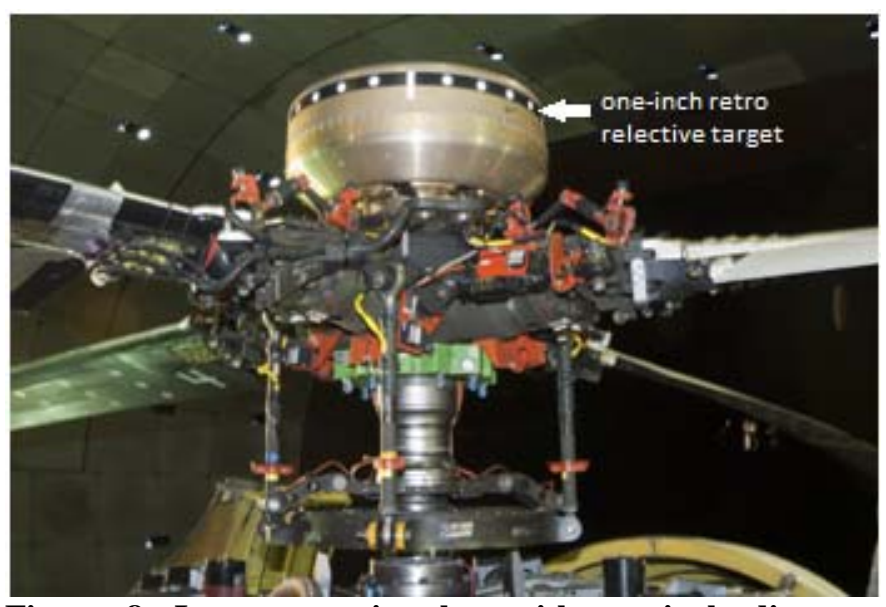

Figure 8. Instrumentation hat with one-inch diameter retro-reflective targets installed.

calibrated shaft angle provided by the NFAC data system, in combination with model support and rotor system geometry. However, if the shaft motion in the plane of the rotor is sufficiently large, an alternate approach for obtaining data transformation is to compute the instantaneously measured target locations relative to the instantaneous location of the shaft. This is accomplished by measuring the location of the shaft for each image set using a ring of retroreflective targets installed on the instrumentation hat located directly above the rotor hub, as seen in Fig. 8. The rotating instrumentation hat, centered on the axis of the rotor shaft, follows the dynamic motions of the shaft. Using least squares to fit a circle through the measured position of multiple targets provides an estimate of the location of the center of the shaft, thereby providing a basis for consistently computing the location of the blade displacement and location relative to the shaft. To date, inspections of photogrammetric results over a range of test conditions show the rotor drive shaft to be essentially stationary.

\section{Image Acquisition and Processing}

\section{A. Image Acquisition}

Time-synchronized digital images from the eight Imperx cameras were captured at resolution of $2048 \times 2048$ pixels. These cameras were positioned in the test section (Fig. 2) to ensure at least two cameras at any given time capture high-quality images of full-length blades. The strobes and cameras were synchronized to trigger with respect to the desired blade azimuth location to a resolution of $0.35^{\circ}$ (degree/rotor encoder count). Images of the four-blades were simultaneously captured by all eight-cameras as the strobe pulses occur within the integration time of the triggered cameras. Image data sets are categorized as either primary or secondary, each capturing particular test conditions. Primary data sets consist of 60 revolutions of data per rotor azimuth, measuring each blade at 40 azimuth locations over the full $360^{\circ}$ of rotation. Secondary data sets consist of 12 images per rotor azimuth, while measuring one blade per rotor quadrant for a reduced set of 11 azimuths over a range of $95^{\circ}$. For the secondary data sets, Blade 1 ranges from $0^{\circ}$ to $95^{\circ}$ azimuth, Blade 2 from $90^{\circ}$ to $185^{\circ}$, Blade 3 from $180^{\circ}$ to $275^{\circ}$, and Blade 4 from $270^{\circ}$ to $5^{\circ}$. Primary data sets required approximately 10 minutes each to obtain while the secondary data sets required about one minute. 


\section{B. Image Processing}

The sequences of images are digitally processed in order to calculate accurate centroid locations of discrete targets on the rotor blades, rotor instrumentation hat, and test section ceiling. A suite of custom designed image processing and data reduction functions were developed using the Matlab software environment. Supporting functions for image processing, photogrammetry, and coordinate transformations are provided via a custom Matlab Photogrammetry Toolbox developed by Western Michigan University (WMU) for NASA. ${ }^{17}$ The WMU Toolbox, in conjunction with Mathworks ${ }^{\circledR}$ Matlab Image Processing and Statistics Toolboxes, are integrated into a NASA rotorspecific toolbox suite of functions. The NASA Rotor Toolbox makes use of moderately automated post-test image processing procedures that identify BD targets and calculates the image plane centroid spatial coordinates for each. For example, user interface is required during the centroiding procedures for the first image of an image sequence due to the movement of the rotor blades about the image plane. Then, determining target centroids from the second image to the end of the image sequence is fully automated. Slowed-rotor, high advance ratio test conditions proved to be particularly challenging due to the extreme image-to-image blade motion (compared to lower advance ratios) especially near the inboard portion of the rotor blades.

\section{Centroid Anomalies}

The location of accurate image plane coordinates (centroids) of targets on the blades is crucial to the measurement process. Anomalies such as targets that appear in several images of an image sequence, but disappear (either fully or partially) in other images of the sequence can exacerbate the automation of the image processing. Figure 9 shows two images from the same image sequence illustrating this condition.

Another problem is the reflection of the xenon strobe light from the BD camera cavity protective windows (Fig. 10). These reflections were reduced by about a factor of four from the previous two NFAC tests by replacing these windows with new low-reflectance coated windows. Even though the reflections were reduced significantly, they can still be problematic. However, these reflections generally only affect a few targets on each blade at a single azimuth position per camera. Rev-to-rev variations in blade position can cause the strobe reflections to intermittently merge with blade targets as indicated by the shaded red area in Fig. 10c. If the grayscale luminance of the target is not sufficiently larger than that of the strobe

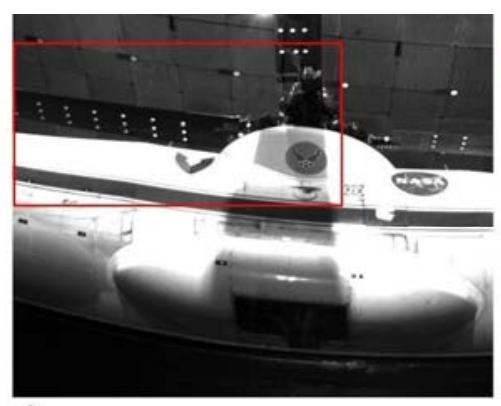

Area viewed in Figs. 9b and 9c

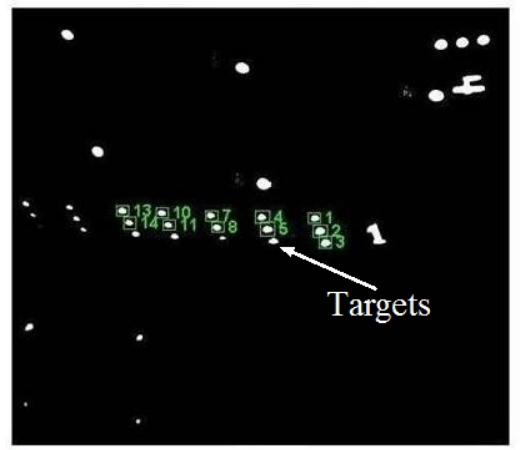

b)

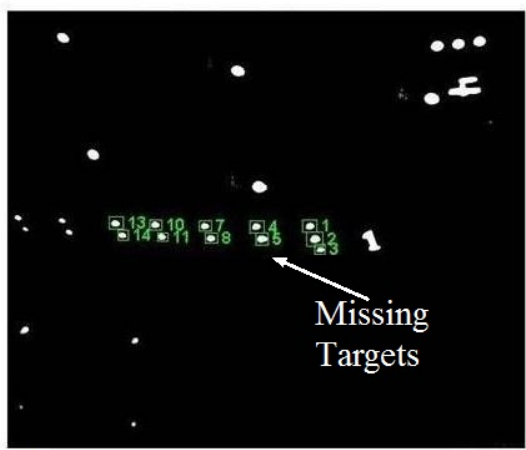

c)
Figure 9. a) Close-up of LRTA and 3 of 4 rotor blades; b) Blade 1 with minimum blockage from LRTA; c) Blade 1 with approx $30 \%$ blockage from LRTA. The bottom row of blade targets cannot be seen in Fig. 9c.

light reflection, the ability to accurately determine the position of the target centroid may be compromised. Effective means for dealing with these problems and improving the level of automation are under study. 


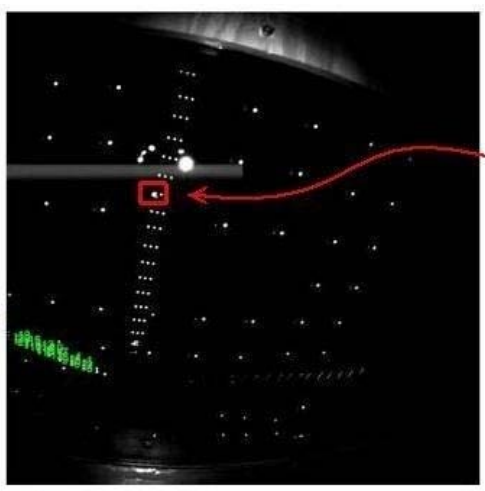

a)

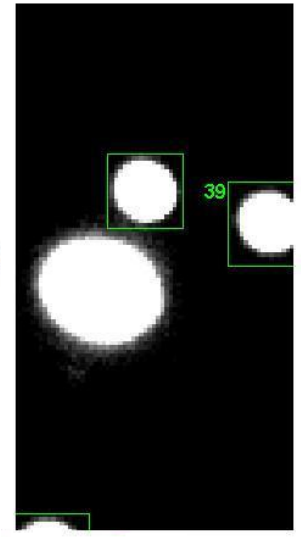

b)

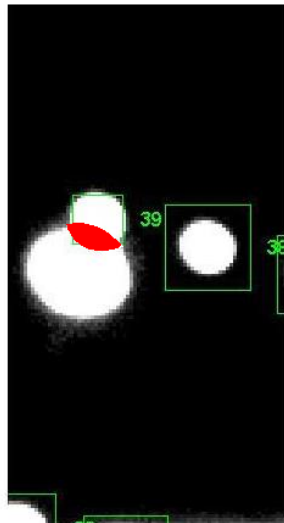

c)

Figure 10. Effect of strobe light reflections on centroiding of targets; a) Typical image with strobe reflection in near vicinity to blade targets b) Image with strobe reflection distinct from target c) Image with strobe reflection overlapping blade target (shaded red identifies an area of combined grayscale).

\section{Preliminary Sample Results}

BD experimental data for the UH-60A Airloads Wind Tunnel Test have been acquired over a large range of test conditions. Once validated, results will be compared to computational predictions as well as flight and scale-model test data. The sample results presented below highlight three preliminary measurements over the full azimuthal range: 1) blade root motion in pitch, flap and lag, 2) elastic deformation in the vertical direction, including rev-to-rev variations and 3) vertical location of the blade tip, showing blade-to-blade differences. The following sample results focus on BD measurements made at one test condition: $\mu=0.3, \mathrm{Ct} / \sigma=0.1$, and a free-stream velocity of 129 knots. For all four blades $0^{\circ}$ azimuth is when the corresponding blade is over the tail of the LRTA.

Bending and twist are often small values superimposed on large rigid-body displacements due to pitch, flap, and lag of the blades at the rotor hinges. Therefore, determining the aerodynamic load-induced elastic bending and twist of the rotor blades is challenging. In order to extract the elastic bending and twist, it is necessary to remove or account for this large hinge induced motion. First the known shaft angle from the NFAC data system is used to mathematically rotate the blade xyz data to facilitate analyses in the rotor shaft coordinate system. Blade target mappings (Section III.C) that define the coordinates of all targets on each blade are then used as a mathematical reference with the inboard $25 \%$ of targets representing the un-deformed blades at zero degrees azimuth. Comparing the inboard $25 \%$ of the BD data and mathematical reference maps with a nonlinear least squares three-dimensional conformal transformation provides three Euler angles and three translations that effectively removes the rigid body displacement. This transformation then defines the inboard pitch, flap, and lag angles that are proportional to these Euler angles (with proper attention given to sign, blade number, and azimuthal restriction of range from $0^{\circ}$ to $359.9 . .{ }^{\circ}$ ). The BD pitch, flap, and lag angles can be compared to more traditionally measured quantities acquired using mechanical blade motion measurement and laser based rotor state measurement systems. ${ }^{5,10}$ These comparisons can help resolve potential discrepancies between the more standard methods, as well as help resolve blade-to-blade discrepancies. Note that the BD measurements are expected to be more reliable for blade-to-blade comparisons as opposed to absolute values for pitch, flap, and lag. This is due to the fact that each set of blade data at a given azimuth uses the same cameras with the blades appearing in nearly the same area of the image plane. Thus any BD bias errors that are common to all four blades will generally be subtracted out when blade-to-blade comparisons are made. 
Figures 11, 12, and 13 contain mean pitch, flap, and lag angles versus azimuth and highlight the blade-to-blade differences. Each of the data points in these figures are ensemble averages of 60 consecutive rotor revolutions. Blade-to-blade differences are emphasized in part b of each figure by subtracting (at each azimuth) the mean values for the four blades. Individual color labels are assigned to the blades in the plots to segregate one blade from another. The standard deviation in pitch (Fig. 11) of the mean blade-to-blade differences over $360^{\circ}$ is $0.18^{\circ}$ with the maximum difference of $0.43^{\circ}$ occurring between blades 1 and 4 . The identification, removal, and/or correction of possible outliers such as those associated with Blade 4 at $175^{\circ}$ and $180^{\circ}$ azimuth, are currently under study.
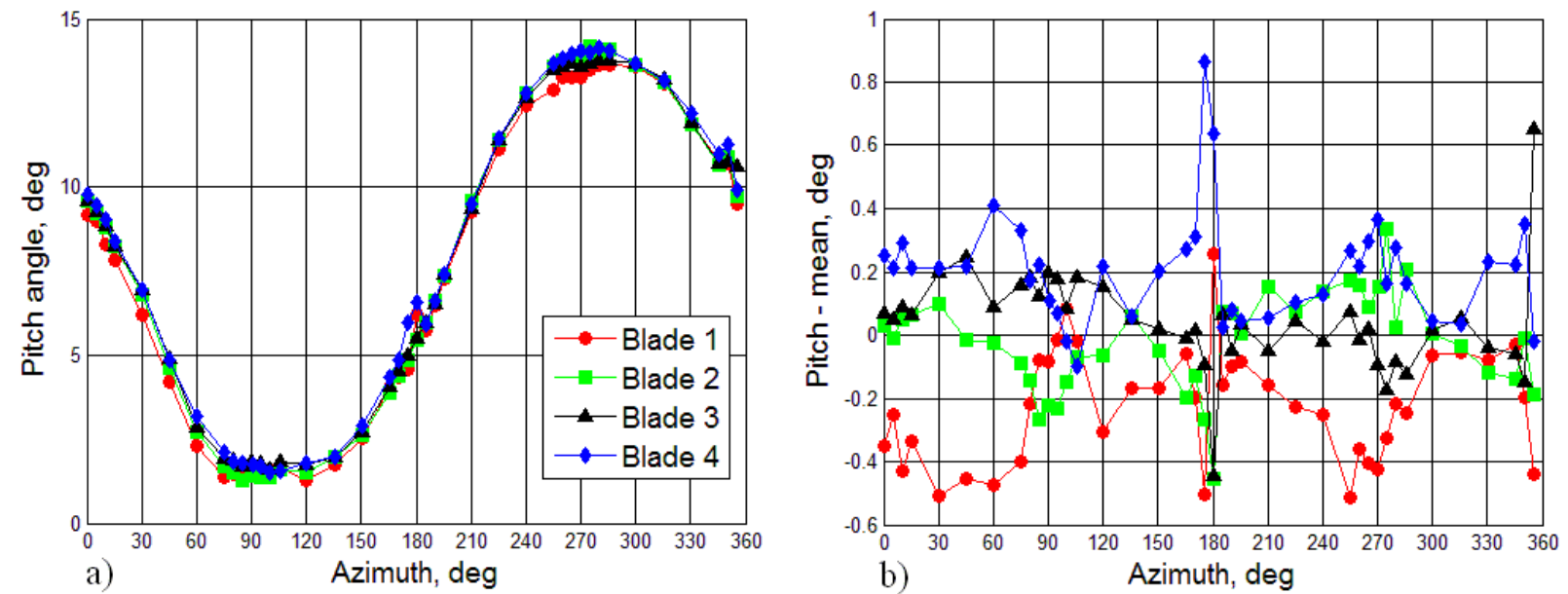

Figure 11. a) Pitch angles over the full azimuth and b) blade-to-blade differences, for $\mu=0.30, C_{T} / \sigma=0.10$.

Flap angle versus azimuth and the corresponding flap angle blade-to-blade differences are shown in Fig. 12. The mean flap angle for all four blades over $360^{\circ}$ is $4.89^{\circ}$ with a standard deviation over the full azimuthal range for individual blades ranging from a low of $0.46^{\circ}$ for Blade 2 to a high of $0.61^{\circ}$ for Blade 3 . The largest flap angle differences occur between Blade 1, the pressure instrumented blade, and Blade 3, the strain gauge instrumented blade, at an azimuth range of $60^{\circ}$ to $270^{\circ}$. The maximum flap angle difference is nearly $1.1^{\circ}$, while the mean values of flap over $360^{\circ}$ for blades 1 and 3 differ by $0.44^{\circ}$. Blades 2 and 4 are in closer agreement than the other blades with a mean value within $0.01^{\circ}$, and a maximum measured difference of $0.17^{\circ}$ at an azimuth of $85^{\circ}$.
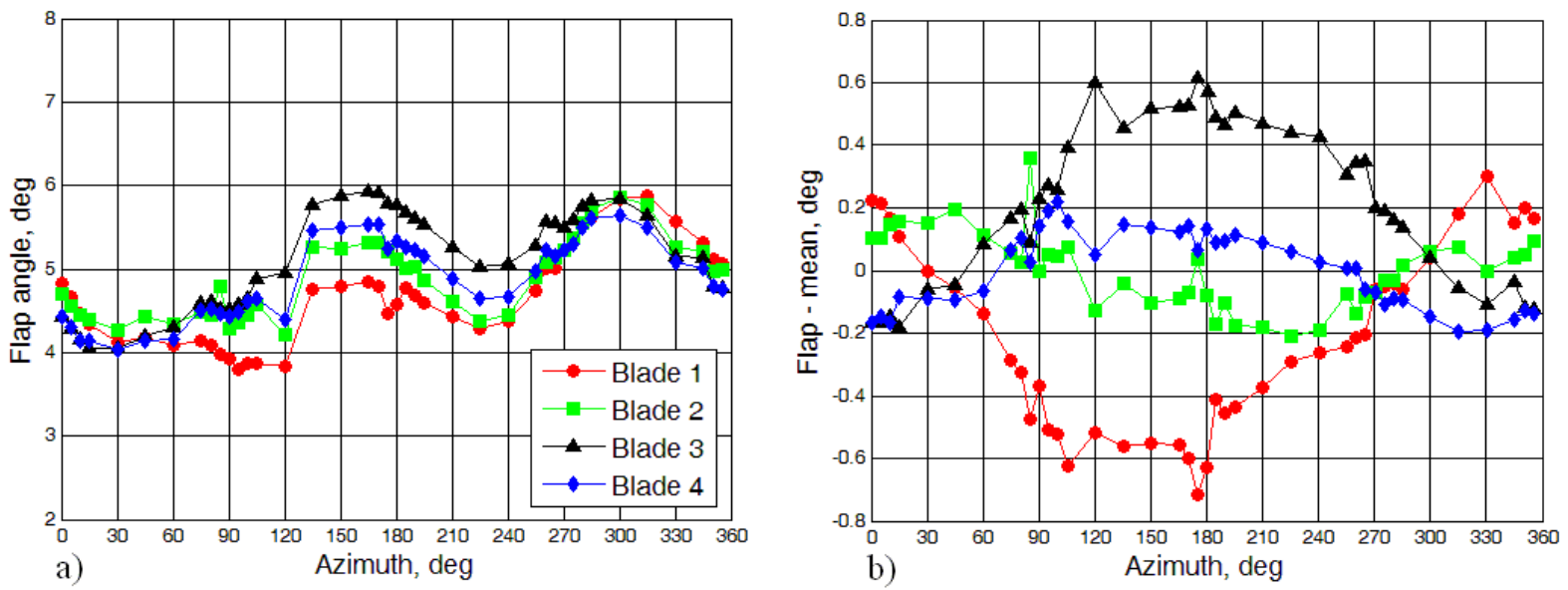

Figure 12. a) Flap angles over the full azimuth and b) blade-to-blade differences, for $\mu=0.30, C_{T} / \sigma=0.10$. 
Lag angle versus azimuth with corresponding blade-to-blade differences are presented in Fig. 13. Here a positive lag indicates that the blade is lagging behind relative to the shaft azimuth angle. The lag data shows blades 1 , 2 , and 4 with similar lag profiles to within $\approx 0.1^{\circ}$, whereas Blade 3 on average leads the mean of the other three blades by $0.32^{\circ}$ independent of azimuth. The standard deviation of the blade-to-blade differences for each blade over the full azimuth are less than $0.06^{\circ}$, which indicates very little blade-to-blade azimuthal variation in lag in addition to providing an estimate of the potential precision in measuring lag.
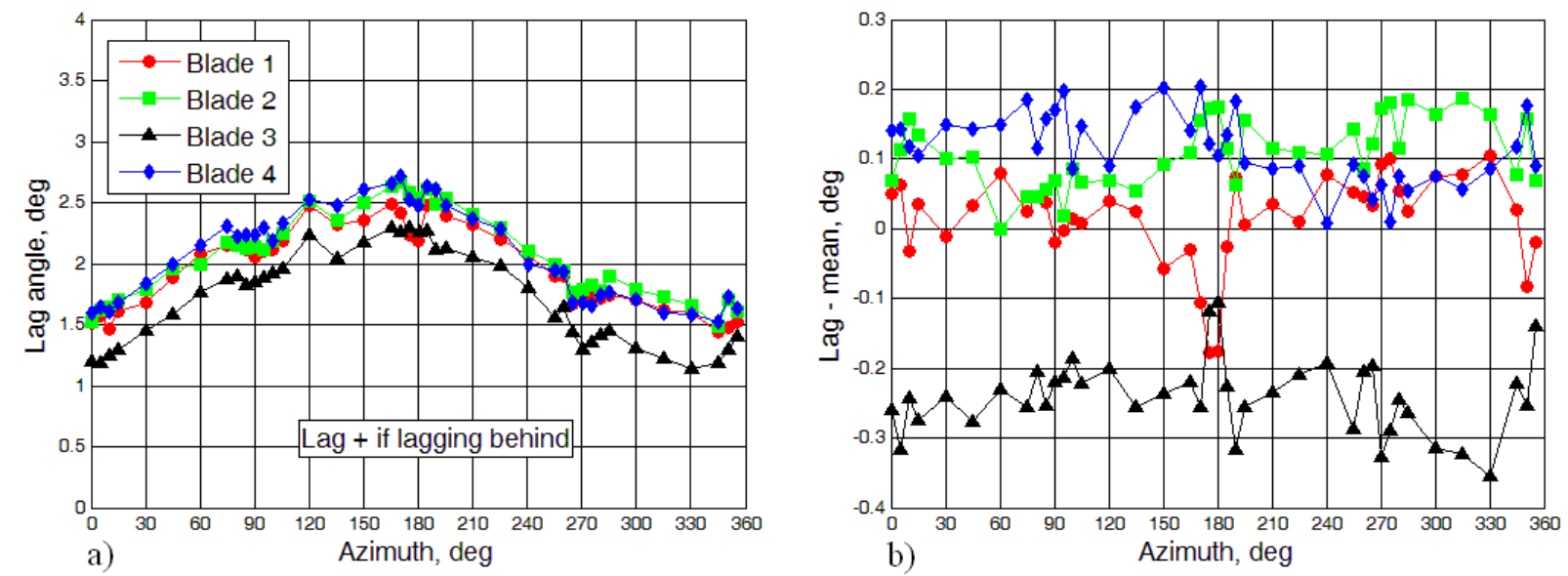

Figure 13. a) Lag angles over the full azimuth and b) blade-to-blade differences, for $\mu=0.30, \mathrm{C}_{\mathrm{T}} / \sigma=0.10$.

When using the three-dimensional transformation coefficients determined from the inboard $25 \%$ of targets the measured xyz coordinates (corrected for shaft angle) can be transformed from the wind tunnel coordinate system to the rotor coordinate system aligned with the reference blade. By subtracting the vertical displacement of the reference blade from the vertical displacement of the transformed blade a first estimate of the spanwise distribution of elastic bending $(\Delta \mathrm{Z})$ is obtained. Examples of elastic bending versus $\mathrm{r} / \mathrm{R}$ are shown in figure 14 at $5^{\circ}, 150^{\circ}$ and $275^{\circ}$ azimuth. Each figure contains data from 60 consecutive rotor revolutions of the Blade 1 leading edge targets, closest to the $1 / 4$-chord. The elastic deformations for the UH-60A rotor are relatively mild at this test condition. The maximum instantaneous elastic bending is less than one-inch over the span of the blade at $5^{\circ}$ azimuth with a mean value of 0.6 inches near the blade tip. At an azimuth of $150^{\circ}$ the mean elastic deformation at the blade tip $(\mathrm{r} / \mathrm{R}$ $=0.97)$ is 15 inches in the downward direction. At an azimuth of $275^{\circ}$ the mean elastic deformation at the blade tip is five-inches in the upward direction.
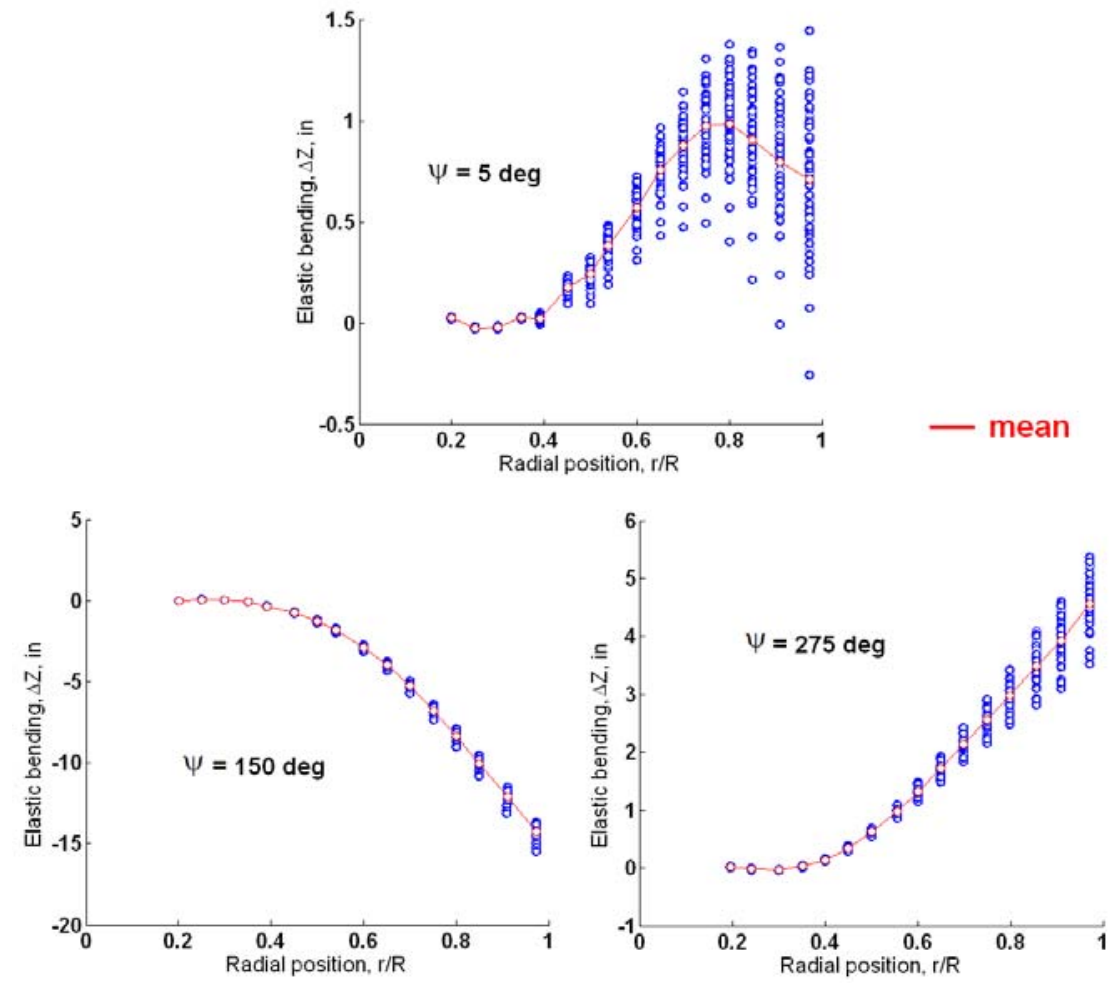

Figure 14. Elastic blade bending for Blade 1 defined by subtracting reference blade data from transformed measured Z-values. Mean values at each azimuth are shown in red on the plots. 


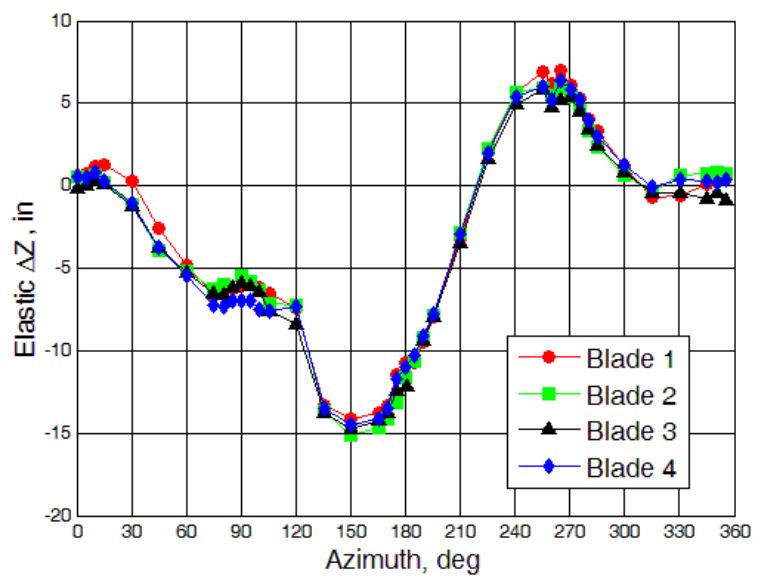

Figure 15. Elastic bending (all blades), $\mathbf{r} / \mathbf{R}=\mathbf{0 . 9 7}$ for $\mu=0.30, C_{T} / \sigma=0.10$.

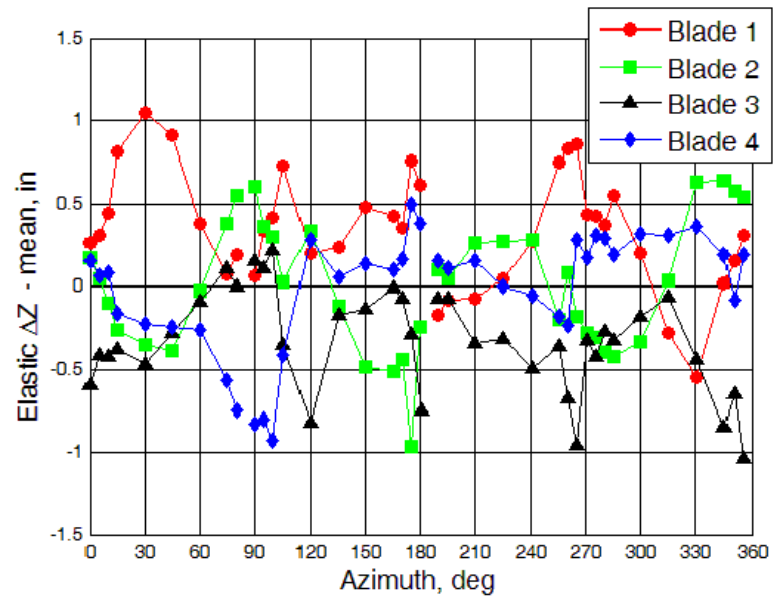

Figure 16. Elastic bending, blade-to-blade differences at $\mathbf{r} / \mathbf{R}=\mathbf{0 . 9 7}$ for $\mu=0.30$, $\mathrm{C}_{\mathrm{T}} / \sigma=0.10$.

The mean elastic bending at the blade tip $(\mathrm{r} / \mathrm{R}=0.97)$ is plotted versus azimuth in Fig. 15. The elastic bending at $\mathrm{r} / \mathrm{R}=0.97$ varies from -15 inches (downward bending) at $\psi=150^{\circ}$ to seven-inches (upward bending) at $\psi=265^{\circ}$. The elastic bending is similar for all blades. In order to emphasize blade-to-blade differences this data is re-plotted in Fig. 16 with the four-blade mean value at each azimuth subtracted out. No azimuthally systematic differences are discernable in this data. The mean bending over $360^{\circ}$ for blades 1 and 3 differ by 0.67 inch, whereas blades 2 and 4 differ by only 0.02 inch. Fig. 17 shows the elastic bending standard deviation for all four blades near the tip at $r / R=$ 0.97. It can be seen from this data that the elastic bending of the blades are not significantly different. The average elastic standard deviation over the full azimuthal range differs by no more than 0.02 inches.

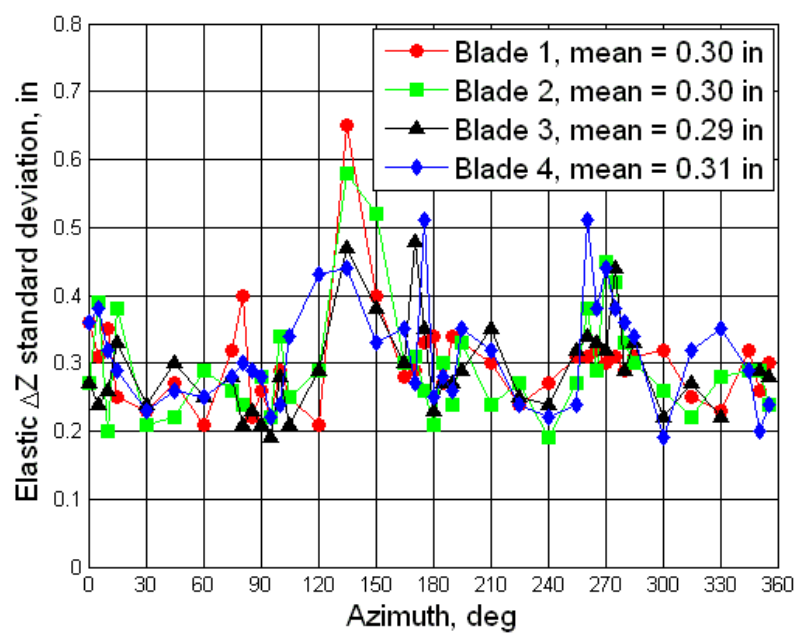

Figure 17. Elastic bending, standard deviation for all 4 blades at $r / R=0.97$ for $\mu=0.30, C_{T} / \sigma=0.10$. 


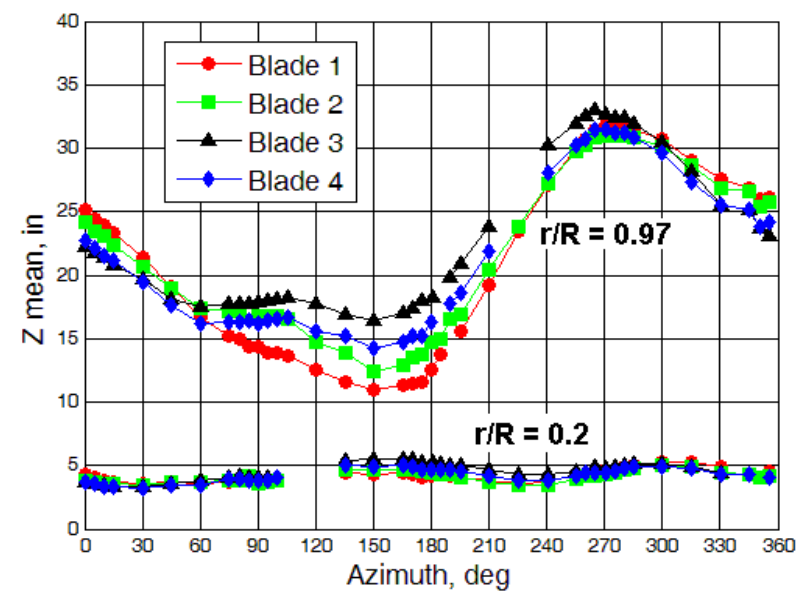

Figure 18. Z-mean, 60 image set, nearest to quarter chord at $r / R=0.2$ and 0.97 for the 4 blades at $\mu=0.30, \mathrm{C}_{\mathrm{T}} / \sigma=0.10$.

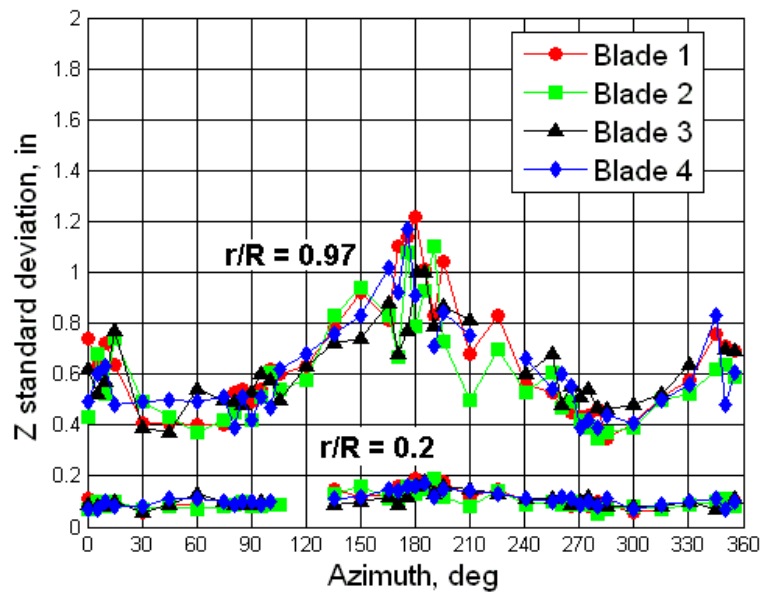

Figure 19. Z-displacement, standard deviations at $\mathbf{r} / \mathbf{R}=0.2$ and 0.97 for the 4 blades at $\mu=0.30, \mathrm{C}_{\mathrm{T}} / \sigma=0.10$.

Figures 18 and 19 show the combined effect of both blade flap and elastic bending. These results are derived from 60 image-set averages of the target nearest the quarter chord to the respective radial stations. The only transformation coefficient applied (other than shaft angle) is the Z-transformation required to align the xyz blade data at azimuth to the reference blade data at $0^{\circ}$ azimuth. Thus only the Z-component is adjusted from the original shaft-angle-corrected xyz data. The mean $\mathrm{Z}$ displacement at the most inboard $(\mathrm{r} / \mathrm{R}=0.2)$ and most outboard $(\mathrm{r} / \mathrm{R}=$ 0.97) radial stations are shown in Fig. 18. A mean (azimuthally averaged) flap angle of $4.89^{\circ}$ results in an inboard station mean value near five-inches and an outboard mean value near 25 inches. As expected the inboard station has a relatively small azimuthal variation whereas the outboard station oscillates about a mean of 25 inches with a range near 25 inches. These results are consistent with the negative elastic bending from approximately $0^{\circ}$ to about $220^{\circ}$ and the positive elastic bending from $220^{\circ}$ to $360^{\circ}$ noted in Fig. 15. Figure 19 shows the standard deviation of the Z-displacement at $\mathrm{r} / \mathrm{R}=0.2$ and 0.97 for the four blades. Note that all of the blades behave dynamically in a somewhat similar manner when both flapping and elastic bending are included. The blade-to-blade differences of the mean $\mathrm{Z}$ at $r / R=0.97$ are shown in Fig. 20 where it is noted that the maximum difference occurs for blades 1 and 3 with a difference in mean $\mathrm{Z}$ of six-inches near $180^{\circ}$. For these test conditions the rev-to-rev variations in blade position between $150^{\circ}$ and $210^{\circ}$ are two to three times those elsewhere in the rotor disk. It is important to note that although Figs. 18 and 20 show blade-to-blade differences in $\mathrm{Z}$ position approaching six-inches (1.87\% of the rotor radius) the blade-to-blade

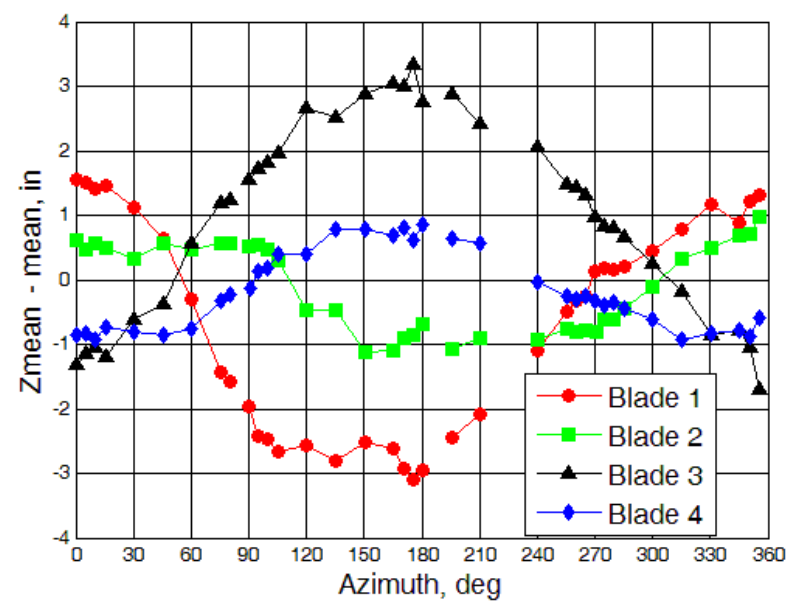

Figure 20. Z-mean, blade-to-blade differences of the leading edge tip target at $r / R=0.97$ for $\mu=0.30, \mathrm{C}_{\mathrm{T}} / \sigma=0.10$. differences in elastic bending are smaller by roughly a factor of five. This indicates that the aeroelastic properties of the four blades are not significantly different. Also, when the Airloads rotor is proportionally scaled, under comparable test conditions, the measured Airloads blade-to-blade differences in flapwise deflection are similar in magnitude to those measured during the HART II tests. ${ }^{18}$ This implies that the blade-to-blade variations in the Airloads test in the NFAC are not atypical and are comparable to those observed in another large-scale facility. 


\section{Concluding Remarks}

The primary objective of this rotorcraft blade displacement work is to obtain accurate data for a range of relevant test conditions that is suitable for validation of CFD/CSD methods capable of simulating full-scale flight conditions. The ability to photogrammetrically measure blade displacement, encompassing a full rotor azimuth and all the blades of a full-scale UH-60A rotor during wind tunnel testing at conditions representative of actual freeflight has been successfully demonstrated. Preliminary measurements over the full azimuthal range have been presented. These measurements include, 1) blade root motion in pitch, flap and lag, 2) elastic deformation in the vertical direction, including mean and revolution-to-revolution variations versus blade span and 3) vertical location of the blade tip, showing blade-to-blade differences. The data indicates that while the blades behave somewhat differently in pitch, flap, and lag, their aeroelastic behavior is not significantly different.

The two system checkout entries at NFAC in 2008 and 2009 were crucial to the success of the BD system during the Airloads Test in 2010. Ongoing data reduction and analysis for rotorcraft has been a challenge, driven primarily by varying target contrast and the need for high accuracy calibrations of the fish-eye lenses necessary for this effort. Although significant progress has been made in automation and robustness of the image processing and data reduction procedures, additional time and effort are required to adequately process, verify image centroids, analyze, and fully understand the data results and implications.

\section{Acknowledgments}

The authors thankfully recognize the efforts and significant contributions made during the planning, developing, and implementing of the blade displacement measurements for Airloads. Acknowledgement is made to Thomas Norman, Gloria Yamauchi, Alan Wadcock (NASA Ames), and Gary Fleming (NASA LaRC) for their early involvement with the BD measurement effort. Gary Fleming also developed and provided assistance with the rotor azimuthal synchronization system RASP. Edward Massey (Jacobs Technology-NASA LaRC) is acknowledged for his modifications to the WingViewer image acquisition software to accommodate special requirements for rotor testing. Further acknowledgement is extended to Luther Jenkins and Odilyn Santamaria-Luck (NASA LaRC) for program leadership and to Harriett Dismond, Kelvin Santiago, Felecia Berry, Kristina Chapman (NASA LaRC), Eduardo Solis, Charles Rogers, Michael Henderson, Benny Cheung, and Dan Christensen (NASA Ames), along with the entire NFAC test team for their strong support of the BD effort.

In addition Thomas Jones (NASA LaRC) is acknowledged for technical advice in camera self-calibration and for calibrations of four of the cameras. Professors Stuart Robson (University College London) and Mark Shortis (RMIT University, Melbourne, Australia) are acknowledged for consultation on the distortion of fish-eye lenses and alternate methods of lens correction. Ethan Romander (NASA Ames) is acknowledged for preliminary computational discussions and comparisons and for suggesting and implementing the best method of lossless image compression to greatly reduce the amount of data storage necessary.

\section{References}

${ }^{1}$ Jenkins, L. N., Barrows, D. A., Cheung, B. K., Lau, B. H., Okojie, R. S., Wadcock, A. J., Watkins, A. N., Yao, C. S., “Chapter 5 - Experimental Capabilities, A Status of NASA Rotorcraft Research”, edited by Gloria K. Yamauchi and Larry A. Young, NASA TP-2009-215369, September 2009.

${ }^{2}$ Schneider, Oliver, and Van der Wall, Berend G., "Final Analysis of HART II Blade Deflection Measurement", 29 European Rotorcraft Forum, Friedrichshafen, Germany, September 16-18, 2003.

${ }^{3}$ Olson, Barrows, Abrego, and Burner, "Blade Deflection Measurements of a Full-Scale UH-60A Rotor System", 2010 AHS Specialists' Conference on Aeromechanics, San Francisco, CA, January 20-22, 2010. ${ }^{5}$ Kufeld, R. M., Balough, D. L., Cross, J. L., Studebaker, K. F., Jennison, C. D., and Bousman, W. G., "Flight Testing of the UH-60A Airloads Aircraft,” American Helicopter Society 50th Annual Forum, Washington D.C., May 1994.

${ }^{4}$ Straub, F. K., Anand, V. R., Birchette, T. S., and Lau, B. H., "Wind Tunnel Test of the SMART Active Flap Rotor", American Helicopter Society 65th Annual Forum Proceedings, Grapevine, TX, May 27-29, 2009.

${ }^{5}$ Yeo, H., Romander, E. A., and Norman, T. R., "Investigation of Rotor Performance and Loads of a UH-60A Individual Blade Control System”, American Helicopter Society 66th Annual Forum Proceedings, Phoenix, AZ, May 11-13, 2010.

${ }^{6}$ Norman, T. R., Shinoda, P., Peterson, R. L., Datta, A., "Full-Scale Wind Tunnel Test of the UH-60A Airloads Rotor," American Helicopter Society 67th Annual Forum, Virginia Beach, VA, May 2011.

${ }^{7}$ Kufeld, R. M., Balough, D. L., Cross, J. L., Studebaker, K. F., Jennison, C. D., and Bousman, W. G., "Flight Testing of the UH-60A Airloads Aircraft,” American Helicopter Society 50th Annual Forum, Washington D.C., May 1994.

${ }^{8}$ Bousman, W. G., and Kufeld, R. M., “UH-60A Airloads Catalog,” NASA TM-2005-212827, 2005.

${ }^{9}$ Luhmann,T., Robson,S., Kyle,S.,A., Harley,I.,A, Close Range Photogrammetry: Principles, Techniques and Applications, John Wiley \& Sons, 2006. 
${ }^{10}$ Fletcher, J. W., and Tischler, M. B., "Improving Helicopter Flight Mechanics Models with Laser Measurements of Blade Flapping,” American Helicopter Society 53rd Annual Forum, Virginia Beach, VA, May 1997.

${ }^{11}$ Gagnon, R., "Sub-Miniature Sensor Installation for UH- 60A Main Rotor Blade Air Loads Flight Test Program,” Presented at the International Telemetry Conference, 1989.

${ }^{12}$ Fleming, G. A., “RASP: Rotor Azimuth Synchronization Program (RASP) User’s Guide, Version 1.3”, NASA Langley Research Center, February 6, 2008.

${ }^{13}$ Amer, T. R. and Goad, W. K., “WingViewer: Data-Acquisition Software for PSP/TSP Wind Tunnel Cameras”, NASA Langley Research Center, LAR-16474-1, Oct 2005.

${ }^{14}$ Burner, A.W., Snow, W.L., Shortis, M.R. and Goad, W.K., Laboratory calibration and characterization of video cameras, SPIE Vol. 1395 Close-Range Photogrammetry Meets Machine Vision, 1990, pp.664-671.

${ }^{15}$ Mikhail, E. M.; Bethel, J. S.; McGlone, J. C., Introduction to Modern Photogrammetry, John Wiley \& Sons, pp. 124-125, 2001.

${ }^{16}$ Geodetic Services, Inc. Web Site (V-STARS system):http://www.geodetic.com/.

${ }^{17}$ Liu, T. and Burner, A. W., "Photogrammetry Toolbox User's Guide”, Western Michigan University in Kalamazoo, MI, May 2007.

${ }^{18}$ Park, Jae-Sang and Jung, Sung Nam, “Comprehensive Multibody Dynamics Analysis for Rotor Aeromechanics Predictions in Descending Flight”, Department of Aerospace Information Engineering, Konkuk University Hwayand-dong, Gwangjin-gu, Seoul 13-701, Korea, 2011. 